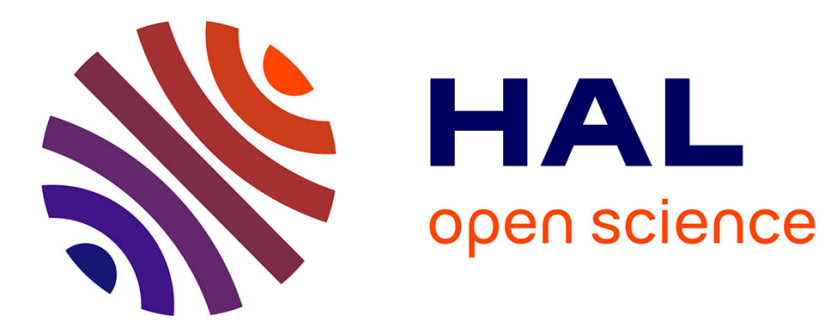

\title{
Minority Influence is Facilitated When the Communication Employs Linguistic Abstractness
}

Harold Sigall, Angelica Mucchi-Faina, Cristina Mosso

\section{To cite this version:}

Harold Sigall, Angelica Mucchi-Faina, Cristina Mosso. Minority Influence is Facilitated When the Communication Employs Linguistic Abstractness. Group Processes and Intergroup Relations, 2006, 9 (3), pp.443-451. 10.1177/1368430206064644 . hal-00571625

\section{HAL Id: hal-00571625 \\ https://hal.science/hal-00571625}

Submitted on 1 Mar 2011

HAL is a multi-disciplinary open access archive for the deposit and dissemination of scientific research documents, whether they are published or not. The documents may come from teaching and research institutions in France or abroad, or from public or private research centers.
L'archive ouverte pluridisciplinaire HAL, est destinée au dépôt et à la diffusion de documents scientifiques de niveau recherche, publiés ou non, émanant des établissements d'enseignement et de recherche français ou étrangers, des laboratoires publics ou privés. 


\title{
Minority Influence is Facilitated When the Communication Employs Linguistic Abstractness
}

\author{
Harold Sigall \\ University of Maryland \\ Angelica Mucchi-Faina \\ Università di Perugia
}

Cristina Mosso

Università di Torino

An experiment tested the hypothesis that minority influence is enhanced when the source of a persuasive communication employs abstract, as opposed to concrete, language. This hypothesis and the research testing it links ideas from two heretofore separate areas of inquiry: minority influence and linguistic abstraction.

It is well known that minority influence increases when the minority is perceived to be consistent. Work on linguistic abstraction has established that when abstract language is used to describe an act, it implies that the act reflects stable, trans-situational characteristics of the actor, whereas concrete language implies that the act reflects isolated, situationally bounded events. We suggest that abstract language therefore conveys greater conviction and thereby increases perceived consistency and, in turn, minority influence.

Source (majority, minority) and language abstractness (abstract, concrete) of a persuasive communication were manipulated. Results revealed that a minority (but not a majority) source was seen as more consistent when using abstract (vs. concrete) language. Although there were no differences among conditions on direct influence, a statistically significant interaction was observed for indirect influence: the abstract-minority source had significantly more indirect influence than did the concrete-minority source, whereas the indirect influence of the majority communicator was not affected by language abstractness.

KEYWORDS indirect influence, linguistic abstraction, minority influence

Some theoretical analyses of minority influence (e.g. Moscovici, 1976) and considerable empirical work (see e.g. Wood, Lundgren, Ouellette, Busceme, \& Blackstone, 1994) make clear that the consistency of the minority plays a very

\section{Author's note}

Address correspondence to Harold Sigall,

Department of Psychology, University of Maryland, College Park, MD 20742, USA

[email: hsigall@psyc.umd.edu] 
important role in minority influence effects. The classical explanation for the contribution of consistency to minority influence is essentially attributional: consistency by a minority conveys courage and commitment. A committed communicator induces more careful message processing, which, in turn, facilitates influence. More recently, it has been proposed that consistency enhances minority influence by promoting attention to the minority view (Crano \& Alvaro, 1998; De Dreu \& De Vries, 1996). According to this argument, minorities are usually overlooked or ignored. By being consistent, i.e. persistently expressing the same view, they draw attention to their position, thereby increasing the likelihood of influence (Wood et al., 1994).

Whereas there may be some uncertainty about the precise mechanism(s) that account for consistency's part in minority influence, the importance of consistency is not in doubt (Maass \& Clark, 1987). But what signals consistency? As Moscovici (1976) noted, consistency is a multidimensional construct: 'it embraces many forms of behaviour, from persistent repetition or phrase, through the avoidance of contradictory behaviour, all the way up to the elaboration of a system of logical proof' (p. 122). One relatively subtle indicator of consistency may be the language one uses when promoting a point of view. The research reported here investigates the possibility that when certain linguistic features are employed by a communicator his or her consistency is strengthened. As a result, such communication should foster minority influence. We are specifically interested in the effects of linguistic abstractness (e.g. Semin \& Fiedler, 1988) on minority influence. Semin and Fiedler (1988, 1989, 1992) developed the linguistic category model to assess cognitive processes that underlie linguistic abstractness. This model distinguishes descriptive action verbs (DAVs), interpretative action verbs (IAVs), state verbs (SVs), and adjectives (ADJs). These four structures, each of which may be applied in the description of the same action, represent, respectively, increasing degrees of abstraction. Thus, e.g. 'I solved the problem', which employs an IAV describes my behavior more concretely (and less abstractly) than 'I am intelligent', which uses an ADJ. Linguistic abstractness has proved to be a very useful concept in understanding a variety of social phenomena (Semin, 1998, 2001), especially in intergroup relations, where the research area has been termed the linguistic intergroup bias (LIB; see e.g. Maass, 1999). For example, it has been demonstrated repeatedly that positive behaviors by ingroup members and negative behaviors by outgroup members are described in more abstract language than are negative behaviors by individuals in the ingroup and positive behaviors by individuals in the outgroup. Maass et al. (1995) found strong evidence that, in general, expectancy consistent behaviors are described at a higher level of abstraction than expectancy inconsistent behaviors. After all, by definition, expected information is more stable, typical, global and diagnostic, and is more appropriately represented in abstract terms.

The interpretation of such effects generally is that the more abstract the language, the more the behavior is being characterized as stable across situations and over time. We argue that in this sense, abstract language can communicate consistency. A communicator who uses abstract language suggests that assertions about actions or events reflect a certain consistency in his or her view. In contrast, the use of concrete language contextualizes the communicator's view, thereby lowering his or her perceived consistency. If the use of abstract language increases the perception of a communicator's consistency, it should facilitate the persuasiveness of a minority communicator. Such consistency is not as important to a majority communicator, who is more able to evoke compliance, and whose position does not violate any expectations.

Moreover, the effect of a consistent minority is more likely to be observed on indirect than on direct influence (Forgas \& Williams, 2001; Mucchi-Faina, 1994; Mugny, 1982). Indeed, indirect influence implies that the recipient of the communication has inferred the underlying guiding principles of the minority position and 
recognizes their validity as an alternative point of view.

Whereas direct influence would be said to occur when an audience is persuaded precisely on the issue that is the manifest focus of the communication (say, increased agreement that the use of recreational drugs should be legalized in response to a communication advocating legalization), indirect influence might be inferred if the same communication persuaded the audience on a related issue (say, that penalties for recreational drug use should be made more lenient). Minority influence is thought to be primarily indirect because people do not wish to be identified with a minority, or considered deviants, and so they resist revealing that they have been influenced directly.

Why doesn't such enhanced consistency also promote the effectiveness of a majority communicator? It is not so much that it couldn't have such an effect-we are not suggesting that consistency is a liability for majority communicators-but that it is unlikely to have the effect because a majority communicator exerts strong social pressure on the audience, and therefore makes the audience's considerations different. The audience is freer to rely on the heuristic, 'Most others agree, so I guess I should'. In addition, the audience's attention may be focused on issues related to yielding to conformity pressure. In either case, the majority communicator is not as likely to induce the kind of processing that minority communicators are known to do. Minority communicators are perhaps more likely to stimulate indirect influence than majority communicators because the latter are not so likely to promote thinking about linked topics (De Dreu \& De Vries, 1996; Erb, Bohner, Schmaelzle \& Rank, 1998).

In the present research, we investigate the possibility that minority influence, especially indirect influence, will be enhanced if the communication is phrased in abstract language. We should note that research on the use of abstract language has generally focused first on what the choice of language reveals about the speakerhow he or she understands the social world, and secondarily on the consequences of the level of language abstraction on the recipient. Thus, in the LIB paradigm, for example, someone is understood to describe a negative act by an outgroup member in abstract terms because that someone views the act as an indicator of a stable quality. The listener, hearing this characterization, will in turn see the outgroup member more negatively than would be so had the act been described more concretely. More recently attention has been directed toward a communicator's choice of language (in terms of abstraction) as a way to influence the communication recipient (Rubini \& Sigall, 2002; Semin, 2000). In the current study, we manipulated language to study its effect on the audience.

The hypothesis was that abstract language would increase minority influence, particularly indirect influence. Underlying this hypothesized effect is the notion that by using abstract language a minority source will be thought to have greater conviction. As noted above, such effects were not expected to be as strong for majority sources.

\section{Method}

\section{Participants and design}

One hundred introductory psychology students (39 men and 61 women) in a large state university in the United States participated in the experiment in return for credit that could fulfill, in part, a course requirement; $94 \%$ of the participants were native speakers of English. In order to test the hypothesis, participants were presented with an influence attempt from a minority or from a majority source, whose communication was phrased in such a way as to minimize or maximize the use of abstract language. Participants were randomly assigned to one of the four conditions created by the 2 (Source: Minority/Majority) $\times 2$ (Linguistic abstractness: Abstract/Concrete) experimental design, and tested individually.

\section{Procedure}

Participants were told that the university's Board of Regents had been considering instituting a required comprehensive examination for all students. If put into effect, students would 
have to pass the examination in order to graduate. It was further explained that the Regents were studying the matter carefully, and that they were gathering views from various interested parties as part of that effort. The research that participants had volunteered for was, broadly speaking, part of that effort, as faculty in the Department of Psychology were interested in the issue.

Prior to being given further information or being subjected to any influence attempt, participants were asked to indicate their position on the following item: 'The [Name of University] should institute a required comprehensive examination'. Responses were made on an 11-point scale that ranged from 'strongly disagree' (1) to 'strongly agree' (11). These responses were collected by the experimenter. Participants were not identified on the response form, nor on the dependent measures that followed.

The experimenter went on to explain that as the participant may have been aware, there had been a number of forums in which interested students were able to present their views on the matter. Manipulations were presented in writing.

\section{Minority/majority manipulation}

Participants were then given a booklet. It indicated that a scientific poll had been conducted to assess student opinion on the question. In the majority condition it was stated that a majority of the campus $(78 \%)$ supported the introduction of the exam; in the minority condition it was stated that a minority of the campus (22\%) supported the exam. Participants then read the arguments of one student who belonged either to the majority or the minority.

\section{Abstract/concrete manipulation}

There were seven arguments presented. The arguments in the abstract language condition were phrased using relatively abstract structures. For example, one argument concerned the comparative employability of students from universities that have a comprehensive examination requirement and those who do not. In the concrete version the phrasing was:
'Students from these universities are recruited (DAV) more by employers', whereas in the abstract condition, the phrasing was, 'Students from these universities are preferred (SV) more by employers'. Thus, there was an effort to keep the content of the abstract and concrete arguments equivalent. The concrete version used DAVs and IAVs exclusively; the abstract version used only SVs and ADJs.

The content of the arguments was guided by previous work using the comprehensive examination issue (Petty \& Cacioppo, 1986). The arguments were pretested on a group of 40 students from the same population as the study participants. Pretest participants were asked to list thoughts generated by the arguments. Arguments for which thoughts were predominantly positive were kept. The language used to manipulate the abstractness variable was chosen by the experimenters and then coded using Semin \& Fiedler's (1988, 1991) linguistic category model by two coders familiar with the system. Intercoder reliability was .90 .

\section{Measures}

After reading the communication, participants again indicated their agreement with the item, 'The [Name of University] should institute a required comprehensive examination'. Responses were made on an 11-point scale, anchored by 'strongly disagree' and 'strongly agree'. This item measured direct influence. The next four items assessed indirect influence. Responses were made on 11-point scales, labeled as indicated below. These questions comprised items that asked whether the university's performance standards should be lowered (1) or raised (11), whether requirements for receiving a degree should be lowered or raised (on the same scale), the extent of their agreement $(1=$ strongly disagree; $11=$ strongly agree) with statements advocating that it is too easy to get high grades at the university and that students found guilty of academic dishonesty should be expelled. These items were chosen as indirect measures of influence because they address whether the university should make increased demands on students, as does the comprehensive examination issue. 
In pretesting with students from the same population, correlations $(r \mathrm{~s})$ between the indirect items and the direct influence item averaged $.28(p<.05)$.

Reactions to the communicator: participants were asked to rate how committed to the position and how consistent, confident, and passionate about the issue the presenter was. Responses were made on 11-point scales, ranging from 'not at all' (1) to 'totally' (11). Participants were also asked how persuasive the communicator would be to students at the university.

To check on whether participants attended to and remembered the minority/majority manipulation, they were asked to 'Estimate the percentage of students on the campus who believe that the university should have required comprehensive exams'. Participants were asked to respond by writing in a number between 0 and 100 , inclusive.

After the measures had been completed, the experimenter probed for suspicion and debriefed participants.

\section{Results}

Participants in the minority influence condition reported, on average, that $24.2 \%(S D=8.73)$ of the students on campus supported the introduction of comprehensive examinations; in the majority condition, the mean was $67.7 \%$ ( $S D=$ 17.14). This difference is statistically significant and shows that the manipulation of minority/ majority influence had an effect $(F(1,96)=$ 244.57, $p<.001)$. There was no effect of language on these estimates: $(F(1,96)=.33$, $n s)$; nor was there an interaction between source and language: $(F(1,96)=1.75, n s)$.

\section{Direct influence}

Prior to the introduction of the experimental manipulations, participants' attitudes toward introducing the comprehensive examination were measured. There were no differences in mean attitude by condition. Subsequent to the treatments, attitudes were measured again. Premeasures were covaried out of the postmeasures, and the adjusted means were calculated: $M=5.88$ in the majority-abstract condition, $M=6.10$ in the majority-concrete condition, $M=6.22$ in the minority-abstract condition, and $M=6.20$ in the minority-concrete condition. As the analysis of covariance showed, there were no effects of either source $(F(1,95)$ $=.68, n s)$ or language abstractness $(F(1,95)=$ $.22, n s)$, and the variables did not interact $(F(1$, $95)=.15, n s)$.

\section{Indirect influence}

As noted earlier, we intended to assess indirect influence with four items, which asked participants about their views on increasing or decreasing performance standards, raising or lowering requirements for earning a degree, whether it was too easy to get high grades in the university's classes, and what they thought was appropriate punishment for academic dishonesty. However, because a reliability analysis yielded a Cronbach's alpha $=.73$ if the item asking about academic honesty was deleted (alpha $=.47$ with that item included), we removed that item; the three remaining individual items used to assess indirect influence were combined to form an indirect influence index. This index was used as the measure of indirect influence in all subsequent analyses.

The correlation between direct and indirect influence was $r=.43$ (99); $p<.001$, which demonstrates that the indirect influence measure was related to the direct measure.

As with the direct measure, we covaried the premeasure out of the indirect measure. The resulting adjusted means on the indirect measure are shown in Figure 1. The minority source had more influence $(M=6.57)$ than did the majority source $(M=6.09)$. This difference was statistically significant $(F(1,95)=4.90$, $p<.05)$. There was no main effect for language abstractness, although there was a tendency for the abstract communication $(M=6.52)$ to be more influential than the concrete $(M=6.13)$ $(F(1,95)=3.49, p<.07)$. The language abstractness by source interaction was in the predicted direction, and statistically significant $(F(1,95)=$ $4.93, p<.05)$. The minority communicator had more indirect influence when the communication used abstract language $(M=6.99)$ than 


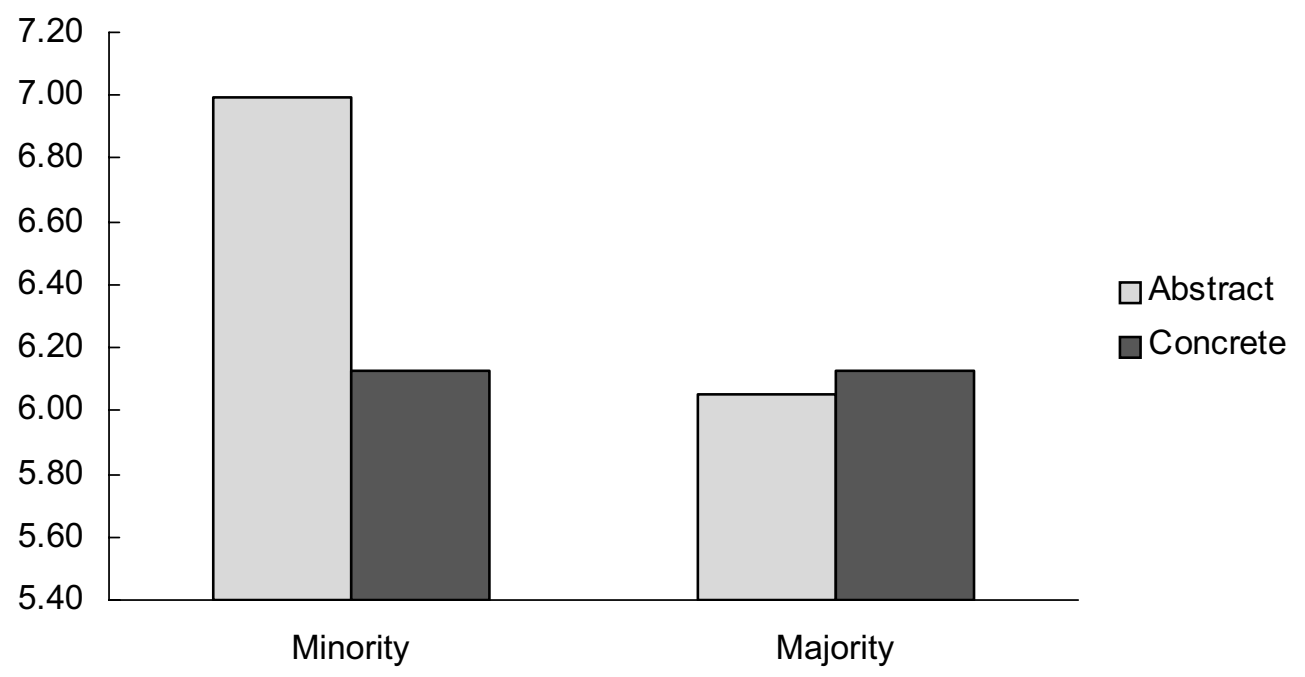

Figure 1. Indirect influence as a function of source and language abstractness.

when it used concrete language $(M=6.13)$; the contrast was significant $(F(1,95)=7.64$, $p<.01)$. However, the influence of the majority source was not affected by language abstractness $(F<1)$.

\section{Perceived consistency}

Participants were asked to rate the communicator on commitment, consistency, confidence and passion with respect to the issue. A reliability analysis indicated that the four items formed a reliable scale (Cronbach's alpha = $.83)$ and the items were combined in a consistency measure.

Because the correlation between the premeasure and perceived consistency was trivial $(r(100)=-.097, n s)$, the premeasure was not covaried out of the perceived consistency measure. For the perceived consistency measure, there was a main effect for language abstractness. Participants in the abstract condition found the source more consistent ( $M=$ 9.08) than did participants in the concrete condition $(M=8.48)(F(1,96)=6.58, p<.05)$. There was no main effect for source $(F(1,96)=$ $1.51, n s)$. The language $\times$ source interaction was significant $(F(1,96)=4.02, p<.05)$. The pattern of the interaction was consistent with our hypothesis: for the minority source the abstract communication led to greater perceived consistency $(M=9.45)$ than did the concrete communication $(M=8.39)$, whereas for the majority source the difference as a function of language was much smaller $(M=$ 8.70 in the majority-abstract condition, and $M=$ 8.57 in the majority-concrete condition-see Figure 2).

\section{Mediation analyses}

Mediation analyses (Baron \& Kenny, 1986) were conducted to examine the possible role of perceived consistency in mediating the relationship between the independent variables and indirect influence. As the primary experimental effect of interest was the language abstractness by source interaction, we tested for mediated moderation. As reported above, the interaction was significant, and the corresponding beta $=-.173, p=$ .043. The interaction effect for perceived consistency, beta $=-.193$, was also significant $(p=$ .027). After controlling for the interaction, perceived consistency was significantly related to indirect influence, beta $=.188, p=.04$. Thus the first three criteria for demonstrating mediation 


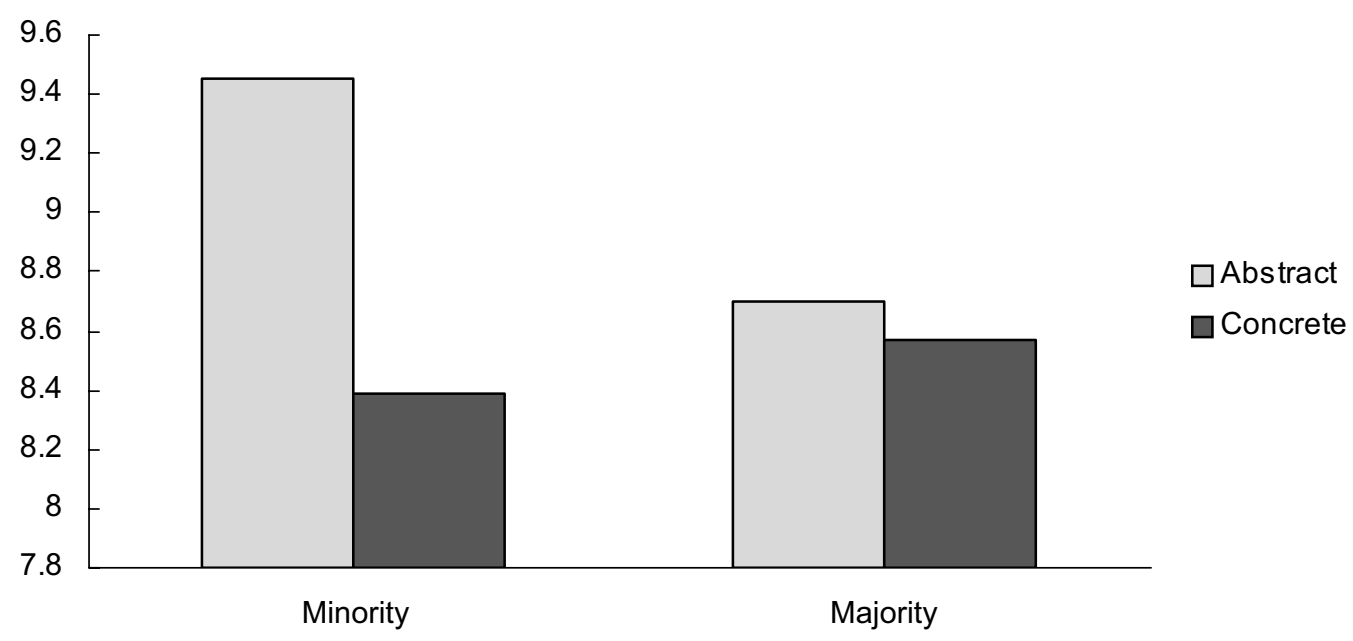

Figure 2. Perceived communicator's consistency as a function of source and language abstractness.

were met. When we controlled for perceived consistency, we found that the beta for the relationship between the interaction and indirect influence dropped from -.173 to -.158 $(p=.082)$. This result suggests partial mediation, but the mediation effect is weak. A Sobel test resulted in a value of $-1.163, p=.24$.

Because the effect of language abstractness was observed primarily in the minority conditions, and because perceived consistency was expected to be important primarily in the minority conditions, we also examined the possibility that perceived consistency mediated that effect. In this analysis we found that the effect of the minority abstract vs. minority concrete conditions on indirect influence yielded a beta $=-.331, p=.008$. The effect of the independent variable on perceived consistency, beta $=-459, p=.001$, was also significant. However, the relationship between perceived consistency and indirect influence, controlling for the independent variable, failed to reach statistical significance, and thus a crucial requirement for demonstrating mediation was not met. It may be that this result reflects a problem of multicollinearity. The relationship between the independent variable (minorityabstract vs. minority-concrete) may be so strong that there is insufficient unique variance in perceived consistency to explain indirect influence.

\section{Discussion}

The main hypothesis examined in this research was that the indirect influence of a minority would be enhanced by the use of abstract language. The results supported this hypothesis. In particular, the interaction between source and language abstractness demonstrated that whereas a minority communicator had more influence when using abstract language than when using concrete language, no such effect occurred when the communicator represented the majority.

The theoretical basis for this prediction rests in part on the idea that abstract language conveys consistency and on Moscovici's (e.g. 1976) analysis of minority influence effects, which stresses the importance of consistency by the minority for improving its persuasive power. The present findings that the minority communicator who used abstract language was seen as more consistent than was the minority communicator who used concrete language, while the perceived consistency of the majority communicator was relatively unaffected by language, fits with our theoretical analysis. The 
formal mediational analyses provided mixed results. Using the criteria set forth by Baron \& Kenny (1986), there is evidence for partial mediated moderation; i.e. the significant relationship between the interaction and indirect influence was reduced to nonsignificance when the mediator, perceived consistency, was controlled for. On the other hand, the nonsignificant Sobel test showed that the degree of mediation was rather modest. When we examine the relationships between the manipulated language variable within the minority source condition and perceived consistency and indirect influence, the criteria for mediation were not met, as the relationship between perceived consistency (with the manipulated variable controlled for) and indirect influence was not significant. Nevertheless, the effect of the independent variable on both perceived consistency and indirect influence was very strong, as Figures 1 and 2 suggest. In sum, indirect influence was enhanced by the use of abstract language by a minority communicator, and that communicator was also viewed as particularly consistent.

As noted earlier, the minority typically fails to achieve direct influence. Although the majority often does obtain such influence, it did not do so in the present experiment. This outcome may very well have been due to certain aspects of the procedure. The premeasure on the direct influence measure was taken shortly before the communication was presented and the postmeasure administered. Thus, commitment to the attitude expressed on the premeasure was likely quite high. We collected the premeasure data when we did to maximize confidence that we knew participant attitudes at the time the communication was introduced. Although we recognized that the timing of the premeasure might make it more difficult to obtain direct influence we pursued this course because we were primarily interested in indirect influence. Although the majority typically has more direct influence than the minority, the majority sometimes fails to have direct influence (Alvaro \& Crano, 1997).

This research links heretofore empirically disparate, but conceptually connected literatures, linguistic abstraction and minority influence, and does so by focusing on the importance of perceived consistency. Thus, an interesting implication of the study lies in the potential for identifying strategies that increase minority influence. Additional research might examine more closely the underlying processes implied by linguistic abstractness theory and how they may be applied to increasing persuasive effectiveness (see also Wigboldus, Semin \& Spears, 2000).

\section{References}

Alvaro, E. M., \& Crano, W. D. (1997). Indirect minority influence: Evidence for leniency in source evaluation and counterargumentation. Journal of Personality and Social Psychology, 72, 949-964.

Baron, R. M, \& Kenny, D. A. (1986). The moderator-mediator variable distinction in social psychology research: Conceptual, strategic, and statistical considerations. Journal of Personality and Social Psychology, 51, 1173-1182.

Crano, W. D., \& Alvaro, E. M. (1998). The context/comparison model of social influence: Mechanisms, structure, and linkages that underlie indirect attitude change. In W. Stroebe \& M. Hewstone (Eds.), European review of social psychology (Vol. 8, pp. 175-202). Chichester, UK: Wiley.

De Dreu, C. K. W., \& De Vries, N. K. (1996). Differential processing and attitude change following majority and minority arguments. British Journal of Social Psychology, 35, 77-90.

Erb, H., Bohner, G., Schmaelzle, K., \& Rank, S. (1998). Beyond conflict and discrepancy: Cognitive bias in minority and majority influence. Personality and Social Psychology Bulletin, 24, 620-633.

Forgas, J. P., \& Williams, K. D. (Eds.). (2001). Social influence: Direct and indirect processes. Sidney: Routledge.

Maass, A. (1999). Linguistic intergroup bias: Stereotypes perpetuation through the language. In M. P. Zanna (Ed.), Advances in experimental social psychology (Vol. 31, pp. 1-30). New York: Academic Press.

Maass, A., \& Clark, R. (1987). Hidden impact of minorities: Fifteen years of minority influence research. Psychological Bulletin, 95, 428-450.

Maass, A., Milesi, A., Zabbini, S., \& Stahlberg, D. (1995). Linguistic intergroup bias: differential 
expectancies or in-group protection? Journal of Personality and Social Psychology, 71, 512-526.

Moscovici, S. (1976). Social influence and social change. London: Academic Press.

Mucchi-Faina, A. (1994). Minority influence effects: Assimilation and differentiation. In S. Moscovici,

A. Mucchi-Faina, \& A. Maas (Eds.), Minority influence. Chicago: Nelson-Hall.

Mugny, G. (1982). The power of minorities. London: Academic Press.

Petty, R. E., \& Cacioppo, J. T. (1986). Communication and persuasion. New York: Springer-Verlag.

Rubini, M., \& Sigall, H. (2002). Taking the edge off of disagreement: Linguistic abstractness and self-presentation to a heterogeneous audience. European Journal of Social Psychology, 32, 343-351.

Semin, G. R. (1998). Cognition, language and communication. In S. R. Fussel \& R. J. Kreuz (Eds.), Social and cognitive psychological approaches to interpersonal communication (pp. 229-257). Hillsdale, NJ: Erlbaum.

Semin, G. R. (2000). Agenda 2000-Communication: Language as implementational device for cognition. European Journal of Social Psychology, 30, 595-612.

Semin, G. R. (2001). Language and social cognition. In A. Tesser \& N. Schwarz (Eds.), Blackwell handbook of social psychology. Intraindividual processes (Vol. 1, pp. 159-180). Oxford, UK: Blackwell.

Semin, G. R., \& Fiedler, K. (1988). The cognitive functions of linguistic categories in describing persons: Social cognition and language. Journal of Personality and Social Psychology, 54, 558-567.

Semin, G. R., \& Fiedler, K. (1989). Relocating attributional phenomena within a language cognition interface: The case of actors' and observers' perspectives. European Journal of Social Psychology, 19, 491-508.
Semin, G. R., \& Fiedler, K. (1991). The linguistic category model: Its bases, applications and range. In W. Stroebe \& M. Hewstone (Eds.), European review of social psychology (Vol. 2, pp. 1-30). Chichester, UK: Wiley.

Semin, G. R., \& Fiedler, K. (1992). Language, interaction and social cognition. London: Sage.

Wigboldus, D. H. J., Semin, G. R., \& Spears, R. (2000). How do we communicate stereotypes? Linguistic bases and inferential consequences. Journal of Personality and Social Psychology, 78, 5-18.

Wood, W., Lundgren, S., Ouellette, J. A., Busceme, S., \& Blackstone, T. (1994). Minority influence: A meta-analytic review of social influence processes. Psychological Bulletin, 115, 323-345.

Paper received 21 July 2003; revised version accepted 14 September 2005.

\section{Biographical notes}

HAROLD SIGALL is professor of psychology at the University of Maryland, College Park. His primary interests are in self-presentation and stereotypes.

ANGELICA MUCCHI-FAINA is professor of social psychology at the University of Perugia. Her main research interests are minority influence, intergroup attitudes and crowd behavior.

CRISTINA O. MOSSO is currently associate professor in social psychology at the University of Turin. Her interests lie in transmission of stereotypes, the dynamics between personal and social identity and, more broadly, psychological and structural factors in intergroup relations. 